\title{
1 Beyond Physical: Cities Living Digital
}

\subsection{Opening}

Ulan Bator, Mongolia. Trichy, India. Choa Chu Kang, Singapore. Los Angeles, USA.

Across these four cities, through the eyes of a young boy, we glimpse our digitally-empowered future.

Adi is seven years old. He lives in Singapore, near the western end, and in public housing. He was the youngest member of Singapore's team at the 2016 Asian Youth Chess Championship held in Ulan Bator, Mongolia.

Adi loves chess. When he talks about chess, his eyes and voice sparkle. Listening to him chirp on and on about opening moves and strategies, you would not have guessed that he only qualified for the national junior chess squad a year ago. Nor that it was barely two years ago that he picked up chess, when a family friend from Los Angeles gave him a simple chess set.

How did he do it? He had a "secret weapon": the World Wide Web. Adi sparred online with top chess players worldwide, many of them older than him, and against advanced computer chess algorithms, until he was good enough to qualify for the squad.

Adi had another "secret weapon": online coaching. Adi loves his online coach, Prab. He had tried out other personal coaches, but 
these did not work out. It was serendipity (and a search engine) that led Adi to Coach Prab. Call it digital chemistry - through Coach Prab, Adi's skills have improved by leaps and bounds. Coach Prab is very proud of Adi's speedy progress.

Coach Prab is based in Trichy, India. He has been coaching chess players since 2005. He also suffers from double kidney failure. Because of infection risks, he is reluctant to leave his house except for dialysis treatment. He thus turned from face-to-face coaching to online coaching, so that he could continue his passion. He now coaches young chess players from over eight countries.

Coach Prab reviews the auto-recorded online games that Adi has played. He discusses where Adi did well and where he did not. Whenever he can, he also watches Adi's online games live, and discusses with him, in real time over Skype, the merits and demerits of each move. Coach Prab even uses online Al analysis to augment his feedback to Adi.

Adi loves that Coach Prab makes him think hard. Adi also loves the sessions where Coach Prab downloads Grandmaster games and explains them to him. He appreciates that he is learning immensely. He believes that he too can be a Grandmaster one day.

Adi's parents could not have imagined how all this has turned out. After all, they are not chess players themselves. They are proud of Adi and grateful to Coach Prab. More importantly, they are pleased that Adi, who used to be shy and bashful, has become more confident and articulate, and has made many friends amongst his peer competitors. 
A boy in Singapore. A coach in Trichy. A competition in Ulan Bator. A friend in Los Angeles. Ignited by interest. Powered by people. Empowered by digital.

They show how cities and citizens could be Living Digital 2040. 


\subsection{Why Living Digital 2040}

For the first time in human history, individuals have access to a wide array of personal, pervasive and powerful digital technologies. What is their impact on the future of cities? And what does this future hold for citizens?

\section{Why Living}

We live digital now. In 1980, MIT Media Lab founder Nicholas Negroponte quipped that "Computing is not about computers any more. It is about living." ${ }^{[1]}$

We saw this coming with smart cities. Singapore Prime Minister, Lee Hsien Loong, for example, envisions the city-state as a Smart Nation where technologies enable people to live and connect with others better. ${ }^{[2]}$

What we have yet to see is how these technologies can change us. MIT Professor and Director of the MIT Initiative on Technology and Self, Sherry Turkle, summed this up when she said:

We saw that we would live digital. What we have yet to see is how these technologies can change us.

"An unstated question lies behind much of our current preoccupation with the future of technology. The question is not what will technology be like in the future, but rather, what will we be like."[3] 


\section{Why Digital}

According to the McKinsey Global Institute, "[t]oday... billions of individuals...are using global digital platforms to learn, find work, showcase their talent, and build personal networks." ${ }^{[4]}$ What "was once largely confined" to advanced cities and companies is now accessible to citizens.

This transforms urban innovation. In the past, only cities and companies could access advanced technologies. They used them to build innovative solutions for urban problems. Citizen participation was limited.

Only cities and companies had access to powerful technologies.

Cities and companies created solutions with technologies.

People participation was limited.
First time in history: you and I have access too, and this unprecedented access will continue to grow.

Citizens create solutions with technologies.

Fig 1.2.1 - How Digital Technologies Have Transformed Urban Innovation 
The advances in personal, pervasive and powerful digital technologies have changed that. Now, citizens can access advanced technologies too. They too can create innovative solutions. They can participate fully as citizen-innovators.

It is no longer just about what cities can do for citizens. It is also about what citizens can do for cities. It is about how cities and citizens can innovate together.

Smart cities are a good start. But much of the current focus is on making what already exists more efficient. It seems to be about doing better, not different. ${ }^{[5]}$

We can do better and different. So we will not only explore how cities and citizens can innovate better. We will also explore how cities and especially citizens can innovate differently.

\section{Creating 2040}

What if we did better and different? Author and activist Jane Jacobs gave us a glimpse into the immense possibilities in her 1961 classic The Death and Life of Great American Cities:

"Cities have the capability of providing something for everybody, only because, and only when, they are created by everybody."[6]

Five decades on, in and through digital technologies, cities have that capability, and everybody can create. Together, cities and citizens could create a very different future for cities and citizens.

It is that future we study in Living Digital 2040. 


\subsection{Why Future of Work, Education, and Healthcare}

When we think of cities, we tend to think of physical locations, places and spaces of the city. These are tangible, visible, and often costly. They grab our attention and consume our imagination.

But the possibilities of digital suggest we need to start thinking more expansively.

Professor Michael Batty from the University College London states in his recent book The New Science of Cities that our understanding of cities should "no longer [be] exclusively based on theories of location". ${ }^{[7]}$ As digital technologies have made possible new interactions and connections across the city and around the world,
Digital technologies

have made possible new interactions and connections across the city and around the world. Living digital means we can go beyond the physical to also focus on interactions, and explore new regional and global possibilities.

"we must underpin our theories with ideas about how we relate to each other... [and] switch our traditional focus from locations to interactions." ${ }^{[7]}$

Living digital means we need to go beyond the physical to also focus on interactions. We need to go social.

We thus focus on work, education, and healthcare. Each is a social institution where many of our interactions and connections are forged. Every citizen experiences them intimately every day or 
at critical stages in their lives. They form a good starting point for examining "ideas about how we relate to each other", ${ }^{[7]}$ and how we might go beyond physical locations.

Thinking beyond the physical and focusing on social interactions also means we can explore new regional and global possibilities. Professor Saskia Sassen of Columbia University writes in her book Cities in a World Economy that we can "specify a variety of transnational geographies that connect specific groups of cities" according to the social and economic processes and activities involved. ${ }^{[8]}$ To her, cities offer another way to understand networks and flows of economic activity, resources, culture, and people. Because of this "proliferation of interurban networks... [t]here is no such entity as a single global city." [8]

Work, education, and healthcare also build human capabilities, as outlined in the diagram on the following page.

Human capabilities are critical: if a city had limited resources and had to choose what to invest in for the long term, building human capabilities is arguably the best bet. ${ }^{[10-19]}$

Digital is also raising pressing questions about work, education, and healthcare. How well citizens do in them determines whether cities thrive or wither.
But digital technologies are raising pressing questions about work, education, and healthcare. ${ }^{[14-19]}$ Will jobs be created or destroyed? Will technology disrupt education and healthcare? Will technology, work, education, and healthcare narrow 


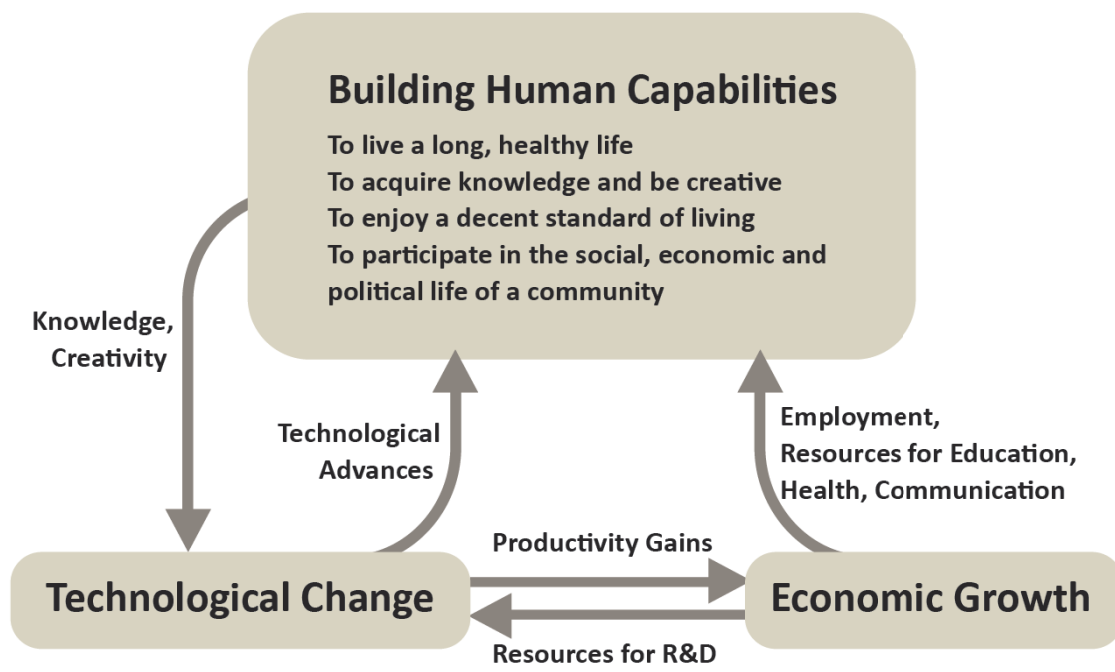

Fig 1.3.1 - Work, Education, and Healthcare Augmented with Technology - Building Human Capabilities in the City.

Adapted from the United Nations Human Development Report 2001 - Making New Technologies Work for Human Development ${ }^{[9]}$

or widen the gap between the haves and have-nots? How cities choose to answer these questions will determine if citizens have the capabilities to create a better future.

We focus on work, education, and healthcare for a third reason: they shape so much of who we are and what we do.

Work provides an income for us and our families. In some cases, it also endows us with the dignity of labour.

Education prepares us for work and life. It hones the intellect, seeds interests, nurtures values, builds character, and develops skills. 
Healthcare makes it possible for us to live life with vigour. It ensures we have the energy and constitution to make the most of our lives.

How well citizens do in work, education, and healthcare determines whether cities thrive or wither. The future of work, education, and healthcare then, is the future of our citizens and our cities. 